\title{
ETIOLOGÍA DEL SÍNDROME NEUMÓNICO AGUDO EN VACUNOS DE ENGORDE EN LIMA
}

\author{
Víctor Zanabria ${ }^{1}$, Hermelinda Rivera G. ${ }^{2}$ y Raúl Rosadio A. ${ }^{2}$
}

\section{Abstract}

Clinical, serological and pathological examinations were conducted on twenty feedlot cattle with acute pneumonia from the Department of Lima, in order to determine the etiology of the disease. Prior to sacrifice all the animals were monitored for clinical signs and sera samples taken for serological testing. At postmortem, all affected lungs were examined grossly and pathological samples were taken to identify viral agents by direct immunoflourescence and/or bacteriological isolation, as well as for histopathological studies. All effected animals exhibited fever $\left(39.41-41.8^{\circ} \mathrm{C}\right)$, tearing, coughing, tachipnea and watery to mucupurulent nasal discharge. Some of these animals $(n=9)$ had dyspneic breathing with open mouth, lingual protrusion and abundant salivation, where as others $(n=11)$ had moderate to severe thriftiness. At necropsy, fibrinous lobar pneumonia involving ventral regions of the apical, intermediate and diaphragmatic lobes was found in all the animals. Histological analyses found eleven cases of acute suppurative bronchopneumonia (Bronchitis, bronchiolitis and alveolitis) and nine cases of fibrinous pleuritis and interstitial pneumonia. Etiopathogenesis studies documented the presence of multiple viral agents plus Pasteurella. Among these, Bovine pestivirus (BVD) was the most common, followed by Bovine Herpesvirus- $1(\mathrm{BHV}-1, \mathrm{n}=15)$ ), Bovine respiratory Syncytial virus (BRSV, $n=7$ ) and Parainfluenza type (PI-3, $n=5$ ). In $95 \%$ of the cases $(n=19)$ virus and bacteria (up to 3 pneumopathogens) were found coexisting in the same affected tissue, with BVDV and BHV-1 plus Pasteurella the most frequent combination. Pasteurella micororganisms were isolated In $55 \%(\mathrm{n}=11)$ of the cases and P. multocida was the most frequented identified. The presence of multiple viral agents was corroborated by the detection of antibodies against BRSV and PI-3 in all the animals tested, as well as the presence of antibodies to BVD in $80 \%(n=16)$ and BHV in $75 \%$ $(n=15)$ of the sample.

Key words: Acute pneumonia, cattle, BVD, IBR, PI-3, BRSV, Pasteurella

\section{Bestumen}

Veinte casos de neumonías agudas de bovinos procedentes de centros de engorde en el Departamento de Lima fueron utilizados con la finalidad de elucidar agentes etiológicos. Con esta finalidad en todos los animales enfermos se realizaron exámenes clínico patológicos, serológicos y al momento del sacrificio se tomaron muestras patológicas para intentar identificar agentes virales (Inmunofluorescencia directa) y/o aislamientos bacteriológicos. Posteriormente, se realizaron minuciosos estudios macro y microscópico a fin de correlacionar las lesiones neumónicas con presencia de agentes microbiológicos. Todos los animales afectados exhibieron fiebre $\left(39.41-41.8^{\circ} \mathrm{C}\right)$, lagrimeo, tos, taquípnea, descarga nasal seroso a mucupurulento.

\footnotetext{
' Facultad de Medicina Veterinaria y Zootecnia, UNA, Puno

'Laboratorio de Microbiologia y Parasitologia - FMV - UNMSM. E.mail: rrosadio@terra.com.pe
} 
Algunos de ellos $(n=9)$ mostraron además respiración disneíca manteniendo boca abierta, protusión lingual, salivación abundante y otros $(n=11)$ moderada a severa depresión. A la necropsia, todos los animales revelaron neumonías lobares, fibrinosas comprometiendo las regiones ventrales de los lóbulos apical, intermedio y diafragmáticos. Estudios histológicos demuestran predominantemente bronconeumonía supurativa de carácter agudo (bonquítis, beonquiolitis y alveolitis) $(\mathrm{n}=11)$ acompañado de pleuritis fibrinosa y neumonía broncointerstitiales $(n=9)$. Los análisis etiopatogénicos revelan la presencia de múltiples agentes virales más Pasteurella. El pestivirus bovino (BVD) fue el virus más frecuentemente identificado $(n=16)$ seguido del herpesvirus bovinos (BHV-1, $\mathrm{n}=15$ ), respiratorio sincitial bovino (BRSV, $\mathrm{n}=7$ ) y parainfluenza $3(\mathrm{PI}-3, \mathrm{n}=5)$. En el 95\% de los casos $(n=19)$ se detectaron la sinergismo virus/ bacteria, fundamentalmente coexistencia de hasta 3 agentes neumopatógenos pero con clara predominancia de la asociación del BVD y BHV-1 mas Pasteurella. En el 55\% $(n=11)$ de los pulmones afectados se aislaron bacterias del género Pasteurella pero con mayor frecuencia $P$. multocida. La presencia de múltiples virus en la población estudiada fue corroborada por la presencia de anticuerpos antivirales en todos los animales muestreados para los virus BRSV y PI3 , y en el $80 \%(n=16)$ y $75 \%(n=15)$ para los virus del BVD y BHV-1 respectivamente.

Palabras clave: Neumonía aguda, vacas, BVD, IBR, PI-3, BRSV, Pasteurella

\section{Introducción}

El complejo respiratorio comúnmente observado en los bovinos son manifestaciones clínicas producto de una secuencial y compleja interacción multifactorial que terminan en procesos bronconeumónicos y/o neumonías fibrinosas. Los factores interactuantes comprenden agentes infecciosos, factores ambientales estresantes y la susceptibilidad del hospedero. La mayoría de brotes neumónicos resulta de la interacción de dos o más microorganismos explotando factores estresantes en el hospedero. El sinergismo patogénico entre virus neumotrópico y bacteria en la producción de cuadros neumónicos es materia de estudio en muchas partes del mundo. La interacción se inicia con el ingreso inicial de un agente viral que destruye o limita los mecanismos de defensa intrapulmonares facilitando la penetración de otro agente viral o permitiendo la colonización y/o proliferación bacterial (Dyer, 1981).

En este contexto, la replicación viral produce daño tisular facilitando una rápida invasión bacterial especialmente por Pasteurellas que terminan por producir cuadros neumónicos agudos fatales. Los virus neumopatógenos son numerosos e involucra al herpes virus bovino de tipo 1 (HVB-1), parainfluenza de tipo 3 (PI-3), respiratorio sincitial bovino (RSB), así como diferentes serotipos de reovirus y adenovirus bovino (Dyer, 1981; Yates et al., 1983). Adicionalmente el virus de la diarrea viral bovina (BVD), de reconocida acción inmunosupresora, está siendo implicado con mucha frecuencia en brotes de enfermedades respiratorias (Evermann et al., 1993).

En el Perú, no se disponen de datos oficiales sobre síndromes neumónicos, pero sin lugar a dudas éstos han aumentado significativamente en los últimos años constituyendo el problema principal en explotaciones bovinas. Estudios serológicos realizado en establecimientos lecheros costeños evidencian que los animales están siendo expuestos a virus neumotrópicos y los casos fatales generalmente se asocia con infecciones por Pasteurella (Rivera et al., 1987). Los problemas neumónicos son muy comunes en explotaciones de engorde alrededores de Lima. Muchos de estos animales enferman y generalmente mueren sin responder al tratamiento quimioterápico. Las pérdidas asociadas resultan no solamente de morbilidad y/o mortalidad, también producen retraso en la ganancia de peso y sobre todo un alto costo en el tratamiento de los animales. 
Los centros de engorde en el Perú son establecimientos ganaderos dedicados a abastecer de carnes rojas a poblaciones urbanas. Los animales proceden mayormente del interior del país, adquiridos en ferias locales, regionales y posteriormente transportados hacia Lima por vía terrestre durante 18-72 horas. El estrés derivado del transporte, crianza en confinamiento y el manejo intenso propio de estas explotaciones desencadenan procesos respiratorios de etiología compleja.

El diagnóstico definitivo de síndromes neumónicos involucra aislamiento $\mathrm{y} / \mathrm{identi-}$ ficación in situ de los agentes neumopatógenos. En este esquema el diagnóstico de los aislamientos virales son excesivamente costosos. Por lo que, la identificación antigénica viral en muestras patológicas es una buena alternativa económica para el diagnóstico de virus neumotrópicos. En este sentido, el presente estudio fue diseñado con la finalidad de identificar agentes infecciosos virales y aislar bacterias directamente de lesiones neumónicas en vacunos de engorde en Lima. La identificación de agentes neumopatógenos virales se correlacionó con presencia de anticuerpos específicos mediante la prueba de suero neutralización viral.

\section{Maternies y Metolos}

\section{Lugar de estudio}

El estudio de campo se realizó en centros de engorde procedentes de los distritos de Lurín y Pachacamac, provincia y departamento de Lima. En estos centros de engorde, el síndrome respiratorio es el principal problema de salud animal. Casi el $50 \%$ de bovinos que arriban enferman y el 10-20\% generalmente mueren o son beneficiadas antes de su comercialización. Los estudios de aislamiento e identificación de agentes patológicos se realizaron en los diferentes laboratorios de la Facultad de Medicina Veterinaria, UNMSM. Algunos exámenes complementarios de histopatología y hematología se realizaron en el laboratorio del Servicio Nacional de Sanidad Agraria (SENASA) y el laboratorio del Instituto Nacional de Salud para algunas pruebas bioquímicas de tipificación de Pasteurellas.

\section{Animales}

Se estudiaron 20 bovinos adultos criollos mostrando signos clínicos de neumonía. El $50 \%$ de estos animales procedían de departamentos norteños (Cajamarca y Lambayeque) y el otro $50 \%$ de Puno. Los animales sin raza definida fueron adquiridos en ferias locales y regionales y transportados durante 18-24 horas (norte) y 48-72 horas (sur) con descansos de 2-3 horas en el viaje. Inmediatamente después del arribo, los animales fueron identificados, descornados, pesados e inyectados con anabólicos, vacuna contra aftosa, ántrax, y tratamiento antiparasitario.

\section{Estudios Clínicos}

Los animales arribaron a los centros de engorde sin mostrar signos aparentes de enfermedad alguna. Después del arribo, los animales fueron observados en busca de alteraciones respiratorias. Los animales sospechosos fueron evaluados clínicamente registrándose temperatura rectal, frecuencia respiratoria, tos, disnea, descarga ocular y nasal, salivación, anorexia, y depresión.

\section{Muestras clínicas y patológicas}

Los animales con diagnóstico presuntivo de síndrome neumónico no recibieron antibioterapia alguna. Estos animales fueron conducidos al camal para practicar la necropsia y realizar exámenes macroscópicos del sistema pulmonar y ganglios linfáticos regionales y proceder a la obtención de muestras patológicas. Paralelamente, se tomaron asépticamente muestras de hisopados nasales y transportados en medios de caldo nutritivos para aislamiento bacteriano. Las muestras sanguíneas $(10 \mathrm{ml})$ se obtuvieron por punción yugular antes de la necropsia. Las muestras 
de suero obtenido fueron inactivadas a $56^{\circ} \mathrm{C}$ por 30 minutos en baño maría y conservado a $-20^{\circ} \mathrm{C}$ hasta el momento de su utilización. Las muestras patológicas (pulmón y ganglios linfáticos regionales), tomados asépticamente, fueron transportados al laboratorio inmediatamente para aislamiento bacteriano y demostración de antígeno viral. Otra porción de tejido afectado fue conservada en formol al $10 \%$ para estudios histopatológicos.

\section{Detección de antígenos virales}

Los virus con capacidad neumopatógena: virus respiratorio sincitial bovino (BRSV), parainfluenza 3 ( PI-3), herpes virus bovino (BHV-1) y virus de la diarrea viral bovina (BVDV) fueron detectados en muestras patológicas por inmunofluorescencia directa utilizando anticuerpos policlonales específicos marcados con fluoresceína.

\section{Prueba de inmunofluorescencia directa (IF)}

Se realizaron cuatro cortes de tejido pulmonar congelados a $-20^{\circ} \mathrm{C}$ utilizando criostato, de un grosor de $5 \mathrm{~mm}$. y tamaño aproximado de $1 \times 1 \mathrm{~cm}$. Los cortes fueron transferidos a láminas porta objetos y fijados en acetona por 12 minutos en refrigeración. Después de secar la lámina y limitarse el tejido fijado con un marcador de látex, se procedió a agregar el conjugado (anticuerpos policlonales marcado con fluoresceína). Cada uno de los tejidos fue sometido con $15 \mathrm{ml}$ de antisueros especificos para identificar antígenos virales perteneciente a los virus BRSV, PI-3, BHV-1 y $\mathrm{BVD}$ respectivamente. Las láminas fueron incubadas por 30 minutos a $37^{\circ} \mathrm{C}$ en una cámara húmeda, lavados con solución salina de fosfato buffer (PBS) (0.1M, pH 7.2) por 5 minutos, enjuagados con agua bidestilada y secado a medio ambiente. El montaje fue realizado agregando 1 gota de líquido de montaje específico. Las lecturas fueron realizados en microscopio de fluorescencia (marca Leitz-Alemania).

\section{Pruebas serológicas}

\section{Prueba de virus neutralización}

Esta prueba se realizó en microplacas de 96 pozos para cultivos celulares utilizando células primarias de comete nasal bovino. Las muestras de suero fueron diluidas doblemente hasta alcanzar dilución final de 1:250 y expuestas a los virus respectivos en suspensiones conteniendo $100 \mathrm{DI}_{50} \mathrm{CC} / 0.050 \mathrm{ml}$. La lectura se realizó a los 4 días pos-incubación e interpretada de acuerdo a la presencia o ausencia de lesiones citopáticas en cada una de los diluciones de los sueros. Los títulos de los sueros fueron expresados como recíprocos de la dilución más alta que neutralizó completamente el efecto citopático viral. Los títulos superiores a 1:2. fueron considerados reacciones positivas a la prueba de suero neutralización.

\section{Aislamientos bacteriológicos}

Los hisopados nasales, muestras de tejido pulmonar y ganglios linfáticos fueron sembrados en agares: Sangre, Mac Conkey y TSA (tripticasa soya agar) e incubados por $18-20$ horas a $37^{\circ} \mathrm{C}$. Las muestras de tejido fueron también utilizados para realizar improntas y coloreadas con la coloración Gram. Las colonias de Pasteurella fueron seleccionadas según sus características culturales teniendo en consideración que la Pasteurella multocida son cocobacilos pequeños, bipolares, gram negativos, no mótiles, no esporulados ni productores de hemólisis, no tienen habilidad de crecimiento en agar Mac Conkey, pero son oxidasa, catalasa e indol positivos. Por otro lado, la Pasteurella haemolytica: cocobacilos pequeños (a veces algo pleomórficos) bipolares, gram negativos, inmóvil, hemolíticas capaces de crecer en agar Mac Conkey, oxidasa y catalasa positivos pero indol negativo. Las caracterizaciones bioquímicas fueron realizadas utilizando API20E y API 20 NE (Laboratorio bioMérieux) (Welmersheimer, 1992; Rimler y Rhoades, 1989; Biberstein et al., 1991). 
Las cepas aisladas fueron mantenidas por pasajes sucesivos semanales en agar sangre a temperatura ambiente. Desde que la temperatura de refrigeración afectó la vitalidad de algunos aislamientos, las cepas fueron congeladas utilizando medios líquidos enriquecidos ( $36 \mathrm{ml}$ de caldo nutritivo y $15 \mathrm{ml}$ de suero estéril de equino) en aliquotas de 3 a $5 \mathrm{ml}$ y conservadas a $-20^{\circ} \mathrm{C}$.

\section{Estudios histopatológicos.}

Las muestras de pulmón y ganglios linfáticos fueron fijadas en formalina neutra al $10 \%$, procesados por la técnica de inclusión en parafina y coloreadas con hematoxilina-eosina para observar y describir las lesiones por microscopía óptica.

\section{Resultanlas}

\section{Signos clínicos}

Los signos clínicos asociados con procesos neumónicos fueron evidentes entre 7 a 15 días posteriores al ingreso de los animales a los centros de engorde. Todos los animales muestreados llegaron a presentar anorexia, temperaturas entre 39.8 a $41.5^{\circ} \mathrm{C}$, taquipnea, tos moderada a severa y no productiva, secreción ocular bilateral transparente, descarga nasal bilateral de serosa a mucopurulenta (Cuadro 1). Sin embargo, en algunos animales ciertos signos clínicos fueron más acentuados que en otros. Once de 20 animales mostraron depresión más severa, caracterizado por orejas caídas manteniendo la cabeza más bajo de lo normal, cierta resistencia a moverse, disnea moderada con tos infrecuente pero dolorosa (Figura 1). En estos animales fueron identificados frecuentemente dos agentes virales (BHV-l y BVDV, PI-3 y BVDV, o BRSV y BVDV) más Pasteurella (Cuadro 4) y las lesiones correspondieron predominantemente a cuadros de bronconeumonía y pleuritis fibrinosa. Por otro lado, 9/20 bovinos mostraron disnea más severa manteniendo la cabeza extendida, respiración por y con la boca abierta, lengua protruída, salivación abundante y descarga nasal copiosa de serosa a mucopurulenta (Figura 2). En estos animales sé llegaron a identificar dos y tres agentes virales coexistemente

Cuadro 1. Signos clínicos observados en el síndrome neumónico del bovino en centros de engorde $(n=20)$

\begin{tabular}{lcc}
\hline \multicolumn{1}{c}{ Signos clínicos } & $\%$ & $\mathrm{n}$ \\
\hline 1. Anorexia & 100 & 20 \\
2. Taquipnea & 100 & 20 \\
3. Temperatura $\left(39.8-41.5^{\circ} \mathrm{C}\right)$ & 100 & 20 \\
4. Tos bronquial profunda & 100 & 20 \\
5. Profusa descarga nasal y secreción ocular & 100 & 20 \\
6. Hiperemia nasal con formaciones costrosas & 75 & 15 \\
7. Depresión severa (cabeza y oreja caídas) & 55 & 11 \\
8. Disnea severa (cabeza extendida, boca abierta) & 45 & 9 \\
9. Opacidad de la cornea & 10 & 2 \\
10. Diarrea & 15 & 5 \\
11. Ruidos pulmonares patológicos & 100 & 20 \\
\hline
\end{tabular}


tales como BHV1 y BVDV; BHV1, BRSV y BVDV ó BHV1, PI-3 y BVDV (Cuadro 4). Las lesiones en estos últimos casos correspondieron en mayor grado a cuadros de bronquitis, peribronquitis y bronquiolitis obliterante, con presencia de células degeneradas e inflamatorias que ocluían las vías aéreas. Finalmente a la auscultación pulmonar, en todos los animales se evidenció aumento en el soplo bronquial, roces pleurales, estertores bronquiales y aún sonidos sibilantes.

\section{Lesiones pulmonares}

Se observaron lesiones extensas típicas de neumonías lobares comprometiendo generalmente regiones anteroventrales de los lóbulos apicales y medios y en menor grado los lóbulos diafragmáticos (Figuras 3 y 4). Todos los pulmones mostraban áreas extensas de consolidación y congestión pulmonar rojizas bien delimitadas del tejido normal acompañados frecuentemente de engrosamiento del septo interlobular, edema, enfisema pulmonar y de pleuritis fíbrinosa (Cuadro 2). La traquea y las vías bronquiales mostraban moderada a severa congestión y hasta hemorragias petequiales así como exudado serofibrinoso mucopurulento. Al corte, en algunos animales, el parénquima pulmonar evidenciaba líquido serosanguinolento. En 5/ 20 casos, la pleura se encontraba hiperémica y mostraba adherencias entre lóbulos y aun unidos al mediastino. Cuatro de estos pulmones fueron positivos a P.multocida $(\mathrm{n}=2)$ y P.haemolytica $(\mathrm{n}=2)$, además de identificarse agentes virales (Cuadro 4). Los nódulos linfáticos de algunos animales estuvieron marcadamente agrandados y edematosos con áreas hiperémicas (Cuadro 2).

Cuadro 2. Frecuencia y porcentajes de las diversas lesiones macroscópicos observadas en bovinos en centros de engorde padeciendo sindromes neumónicos $(n=20)$

\begin{tabular}{lcc}
\hline \multicolumn{1}{c}{ Lesiones } & $\%$ & $\mathbf{n}$ \\
\hline Consolidación pulmonar & 100 & 20 \\
Edema pulmonar moderado a severo & 90 & 18 \\
Enfisema pulmonar leve a moderado & 90 & 18 \\
Engrosamiento septo interlobular & 90 & 18 \\
Formaciones membranosas en las vías altas & 75 & 15 \\
Congestión de mucosa traqueo-bronquial & 75 & 15 \\
Pleuritis fibrinosa & 70 & 14 \\
Hemorragia de mucosa traqueo-bronquial & 25 & 5 \\
Adherencias pleurales & 25 & 5 \\
Focos de microabsceso pulmonar & 20 & 4 \\
\hline
\end{tabular}

\section{Lesiones histopatológicas.}

La mayoría de estos cambios correspondieron en grados variables de inflamaciones en las células de recubrimiento del árbol bronquiolar, alveolar y algunas veces comprometiendo septos interlobulillares.
Las infecciones produjeron cuadros de bronquitis y bronquiolitis caracterizado por severa degeneración y necrosis difusa del epitelio ciliado y no ciliado (Figura 7). Muchas de estas células epiteliales se visualizaron descamadas y otras mostraron degeneración vacuolar. En 9/20 de los pulmones afectados, 
los cuadros de bronquitis y bronquiolitis estuvieron acompañadas por infiltración mononuclear linfocítica multifocal (peribronquiolitis). Entre estos, 6/20 presentaba estructuras polipoides en la luz bronquiolar (bronquiolitis obliterante) (Figura 8) e hiperplasia epitelial de aspecto desorganizado (Cuadro 3). El exudado observado fue mixto compuesto por mononucleares, células descamadas, eritrocitos, edema y escasos neutrófilos. Algunos de estos bronquiolos en los mismos pulmones mostraron hiperplasia epitelial. Las lesiones a nivel alveolar, mostraron severo y difuso engrosamiento del septo interalveolar, edema, necrosis focal difusa e infiltración de células inflamatorias predominantemente mononu-cleares acompañado de congestión y proliferación multifocal de neumocitos de tipo II. La luz alveolar también presentó grados variables de edema, fibrina, formación de membranas hialinas, y material lipoproteinaceo con algunas infiltraciones de eritrocitos y linfocitos (Figuras 5 y 6 ). En sólo 3/20 pulmones se logró visualizar corpúsculos de inclusión y formación de células multinucleadas en sólo 5/20.

En los pulmones con aislamiento de Pasteurella (11/20), los cuadros de bronquitis y bronquiolitis fueron más severos y difusos. Estas lesiones se caracterizaron por presencia de exudado mixto compuesto por neutrófilos, células descamadas, macrófagos, fibrina, linfocitos, eritrocitos y en algunos casos hemorragia moderada y difusa. Los alvéolos y septoalveolar mostraron edema moderada localmente extensiva, acompañado de abundante fibrina e infiltración de células inflamatorias predominantemente polimorfonucleares. Marcada dilatación de los vasos linfáticos y sanguíneos, con múltiples trombos fibrinosos, focos de necrosis coagulativa especialmente en pulmones positivos a P.haemolytica, donde además los cuadros de pleuritis fibrinosa y dilatación del septo interlobular fueron más severos. La mayoría de pulmones mostraban áreas de moderada a severas pérdida de arquitectura pulmonar de y la mayoría de los ganglios linfáticos con grados variables de despoblación linfoide.

Detección de antígeno viral Inmunofluorescencia directa (IF).

En todos los pulmones neumónicos se detectaron agentes neumopatógenos. En el 80\% de estos casos $(\mathrm{n}=16)$ se identificaron antígenos correspondiente al virus del BVD, el $75 \%$ $(\mathrm{n}=15)$ contenían herpesvirus bovino (BHV-1), el $35 \%(n=7)$ BRSV y el $25 \%(n=5)$ PI-3. En el $75 \%(n=15)$ se identificaron simultáneamente 2 agentes virales, en el $20 \%(n=4)$ tres virus y en una muestra solamente al BHV-1. Los tipos de reacciones fluorescentes a nivel celular se muestra en las Figuras 9 y 10.

\section{Aislamiento de Pasteurella}

En el 55\% de los casos ( $\mathrm{n}=11$ ) se aislaron microorganismos del género Pasteurella. De estos, el $73 \%(\mathrm{n}=8)$ correspondieron a $P$. multocida y el restante $(\mathrm{n}=3)$ a $P$. haemolytica. Cuando se utilizaron exudados nasales como fuente de recuperación bacterial, los aislamientos bacteriales se elevaron a $70 \% \quad(n=14)$ y con predominancia de $P$. multocida $(\mathrm{n}=9)$ y los 5 restantes $P$. haemolytica.

\section{Interacción de Virus - Pasteurella.}

En el $95 \%$ de los pulmones neumónicos $(\mathrm{n}=19)$ se observaron sinergismo o asociaciones virales (Cuadro 4). Este sinergismo revela que predomina la presencia de dos virus $(n=15)$ y en los 4 casos restantes coexistencia de hasta 3 virus. En las combinaciones agentes virales duales predomina la existencia del herpesvirus bovino (BHV-1) asociado preferentemente con el virus BVD y en las combinaciones triples el pestivirus (BVD) es el más frecuente pero en todas siempre asociada con el BHV-1 (Cuadro 4). En las interacciones virus/ Pasteurella, se observa con mayor frecuencia dos virus más bacteria $(n=8)$ seguidos de tres virus y Pasteurella $(n=2)$ y en un sólo caso asociación simple de un virus más bacteria. 
Cuadro 3. Alteraciones histopatológicas en pulmones de bovinos afectados con procesos neumónicos $(\mathrm{n}=20)$.

\begin{tabular}{|c|c|c|}
\hline Ubicación & $\%$ & $\mathbf{n}$ \\
\hline \multicolumn{3}{|l|}{ Bronquios: } \\
\hline Bronquitis & 75 & 15 \\
\hline Bronquiolitis & 90 & 18 \\
\hline Peribronquiolitis & 45 & 9 \\
\hline Bronquiolitis obliterante & 30 & 6 \\
\hline \multicolumn{3}{|l|}{ Alvéolos: } \\
\hline Alveolitis & 100 & 20 \\
\hline Edema & 75 & 15 \\
\hline Membranas hialinas & 35 & 7 \\
\hline Fibrina & 55 & 11 \\
\hline Lipoproteinosis & 35 & 7 \\
\hline Hemorragia & 40 & 8 \\
\hline Congestión & 100 & 20 \\
\hline \multicolumn{3}{|l|}{ Tabique interlobulillar: } \\
\hline Aumento de grosor & 100 & 20 \\
\hline \multicolumn{3}{|l|}{ Vasos: } \\
\hline Dilatación & 100 & 20 \\
\hline Congestión & 55 & 11 \\
\hline Trombos & 35 & 7 \\
\hline \multicolumn{3}{|l|}{ Pleura: } \\
\hline Pleuritis & 70 & 14 \\
\hline \multicolumn{3}{|l|}{ Otros: } \\
\hline Cuerpos de inclusión & 15 & 3 \\
\hline Células multinucleadas & 25 & 5 \\
\hline Pérdida de arquitectura pulmonar & 60 & 12 \\
\hline Focos de necrosis & 20 & 4 \\
\hline
\end{tabular}

En general, el sinergismo más común en estas muestras fueron BVDV y BHV1. Sin embargo, en 11 de estos casos se comprobaron interacción virus/bacteria. En estos casos se detectó preferentemente el virus BVD $(n=7)$ asociado con el virus BHVV-1 y Pasteurella $(n=5)$ y PI- 3 mas Pasteurella $(n=2)$
(Cuadro 4). En estas interacciones complejas predominan las combinaciones de BVDV, P.multocida y BHV1. Estas observaciones indican que los síndromes neumónicos en bovinos de engorde en el Perú, son resultado de una secuencial y compleja interacción de dos o más agentes neumopatógenos. 
Cuadro 4. Asociación de virus y Pasteurella en pulmones neumónicos de bovinos de centros de engorde $(n=20)$.

\begin{tabular}{clcc}
\hline $\begin{array}{c}\text { Agentes } \\
\mathrm{N}^{\circ}\end{array}$ & Interacción de especies virales y pasteurella & $\%$ & $\mathrm{n}$ \\
\hline \multirow{2}{*}{2} & & & \\
& BHV1 - P.multocida & 5 & 1 \\
& PI3-BHV1 & 5 & 1 \\
& BRSV-BHV1 & 5 & 1 \\
& BHV1-BVDV & 25 & 5 \\
\hline 3 & PI3-BRSV - P.multocida & 5 & 1 \\
& PI3-BVDV - P.haemolytica & 5 & 1 \\
& PI3-BVDV - P.multocida & 5 & 1 \\
& BRSV-BVDV - P.multocida & 10 & 2 \\
& BHV1-BVDV - P.multocida & 10 & 2 \\
& BHV1-BVDV - P.haemolytica & 5 & 1 \\
& PI3-BHV1-BVDV & 5 & 1 \\
& BRSV-BHV1-BVDV & 5 & 1 \\
\hline & BRSV-BHV1-BVDV - P.multocida & 5 & 1 \\
\hline
\end{tabular}

\section{Hallazgos serológicos}

\section{Virus Neutralización}

Todos los bovinos afectados por procesos neumónicos tenían anticuerpos para el virus del BRS y PI-3 (títulos 2 a 250). El 75 y el $80 \%$ de los animales, igualmente, tenían anticuerpos para el BHV1 y el BVD respectivamente (Cuadro 5). La mayoría de estos animales $(n=12)$, tenían simultáneamente anticuerpos a los 4 virus neumopatógenos estudiados, 7 reaccionaron positivamente a 3 virus y un solo animal a un 1 virus (Cuadro 6). La inversa de los títulos de anticuerpos demuestran que el $57 \%$ de los animales tenían títulos $1: 2$ a $1: 16$ y el $32 \%$ restante mostraron títulos mayores a 1:16 (Cuadro 7).

\section{biscusten}

Las neumonías son, probablemente, las causas de pérdidas más significantes en la ganadería bovina mundial. Las incidencias, sin embargo, varian de un lugar a otro y la etiopatogenia es producto de la interacción de muchos factores incluyendo hospedero, agente neumopatógeno y el medio ambiente. Dentro de la multiplicidad de factores, el agente es sin lugar a dudas el factor determinante y responsable de la severidad clínica de la neumonía observada en el campo.

El diagnóstico de síndromes neumónicos en bovinos es complejo. Si bien es cierto que la dificultad respiratoria es una 
Cuadro 5. Anticuerpos neutralizantes a la prueba de virus neutralización ( $\mathrm{n}=20$ bovinos).

\begin{tabular}{lllllllll}
\hline Animales & \multicolumn{8}{c}{ Títulos Neutralizantes } \\
& \multicolumn{2}{c}{ BRSV } & \multicolumn{2}{c}{ PI-3 } & \multicolumn{2}{c}{ BHV-1 } & \multicolumn{2}{c}{ BVDV } \\
\hline \multirow{3}{*}{ Positivos } & $<2$ & $2-256$ & $<2$ & $2-256$ & $<$ & $2-256$ & $<2$ & $2-256$ \\
& & 20 & 0 & 20 & 5 & 15 & 4 & 16 \\
\hline$\%$ & 0 & 100 & 0 & 100 & 20 & 75 & 20 & 80 \\
\hline
\end{tabular}

Cuadro 6. Animales reactores a 2 ó más virus concomitantes. Prueba de virus neutralización.

\begin{tabular}{ccccc}
\hline Animales & \multicolumn{5}{c}{ Bovinos reactores, $\mathrm{n}$} \\
\hline Positivos & 1 Virus & 2 Virus & 3 Virus & 4 Virus \\
\hline$(\%)$ & 0 & 1 & 7 & 12 \\
\hline
\end{tabular}

Cuadro 7. Frecuencia de títulos séricos antivirales respiratorios $(\mathrm{n}=20$ bovinos $)$.

\begin{tabular}{ccccccccccc}
\hline \multicolumn{10}{c}{ Inversa de los títulos de anticuerpos - Virus neutralización } \\
\hline Virus & $\mathrm{N}$ & $<2$ & 2 & 4 & 8 & 16 & 32 & 64 & 128 & $>250$ \\
BRSV & 20 & 0 & 2 & 3 & 4 & 4 & 1 & 2 & 2 & 2 \\
PI-3 & 20 & 0 & 0 & 2 & 5 & 4 & 1 & 4 & 1 & 3 \\
BHV-1 & 20 & 4 & 3 & 2 & 2 & 0 & 6 & 1 & 0 & 0 \\
BVDV & 20 & 5 & 5 & 2 & 5 & 2 & 0 & 2 & 0 & 0 \\
\hline (\%) & & 45 & 50 & 45 & 80 & 50 & 40 & 45 & 15 & 25 \\
\hline
\end{tabular}

evidencia clínica del proceso neumónico, estas alteraciones clínicas aisladamente no ayudan a determinar los posibles agentes neumopatógeno. Consecuentemente, el diagnóstico etiopatogénico de los problemas respiratorios debe integrar, además del clínico, análisis serológico, microbiológico y cuando sean posible exámenes de posmortem incluyendo observaciones microscópicas e identificación de agentes causantes.
En el presente estudio, se intentó correlacionar estudios clínicos y serológicos con las lesiones macro y microscópicos de los pulmones afectados por cuadros neumónicos e identificación $\mathrm{y} / \mathrm{o}$ aislamientos de agentes microbiológicos. Los casos de neumonías utilizados en este estudio corresponden a los que los ganaderos describen como casos neumónicos típicos. La sintomatología de estos casos, sin embargo, 
varió en su presentación (Cuadro 1). Algunos de éstos $(9 / 20)$ correspondieron a cuadros descritos como edema y enfisemas pulmonares agudas (cabeza extendida, nariz dilatada, respiración por y con la boca abierta, lengua protruída) que podrían bien ser producto de hipersensibilidad o consecuencia de neumotoxicidad (Pierson y Kainer, 1980). Todos estos casos, sin embargo, fueron de carácter infeccioso puesto que los animales presentaron temperatura elevada $\left(39.8-41.8^{\circ} \mathrm{C}\right)$, lesiones obstructivas de las vías aéreas mas presencia de anticuerpos antivirales. Otros animales mostraron signos asociados o descritos como la fiebre del embarque (severa depresión, cabeza y orejas caídas, resistencia a movimiento, secreción nasal mucopurulenta). Estos últimos signos tienden asociarse a compromiso extensivo de parénquima pulmonar y pleura y/o consecuencia de liberación extensiva de endotoxinas de bacterias tales como Pasteurella (Yates et al., 1983; Rimler y Rhoades, 1984)

Las alteraciones patológicos macroscópicos correspondieron predominantemente a bronconeumonías (neumonías lobares o neumonías aspirativas) que comprometían la pleura y caracterizadas por formaciones fibrinosas o seudomembranas (Cuadro 2). Muchos de estos casos evidenciaron cambios evidentes de formación de edema y enfisema pulmonar así como engrosamiento de septos interlobulares. Estas distintas patologías no solamente corresponden a las descripciones de neumonía aguda de alta fatalidad, corresponden también a las descritas como verdaderos síndromes neumónicos que sugerían la presencia de múltiples agentes neumopatógenos. La formación de abundantes focos necróticos con formaciones costrosas en las vías altas y presencia de exudado fibrinopurulento abundante ocluyendo parcialmente la tráquea y bronquios son compatibles con infecciones experimentales herpéticas (BHV-1). Sin embargo, las lesiones lobares consistentes con congestión, consolidación pulmonar, formación de abscesos focales más pleuritis fibrinosa adheridas a las paredes costales han sido observadas mayormente en inoculaciones experimentales de Pasteurella (Welmersheimer, 1992; Martínez et al., 1988; Pedroso et al., 1988; Muñozet al., 1987).

Las lesiones microscópicas, sin embargo, no muestran alteraciones histológicas características de cada agente infeccioso en particular. Los agentes virales tienden a producir reacciones predominantemente intersticiales comprometiendo bronquios y bronquíolos. Mientras que la mayoría de las bacterias promueven formaciones fibrinosas e infiltración granulocítica (Trigo, 1991; Kimman et al., 1989; Yates et al., 1983). Los cambios histopatológicos encontrados en el estudio revelan una gama de complejas lesiones que comprometen diversos estratos del epitelio traqueo bronquial y/o alveolar en diversos grados que probablemente sean consecuencia de diferentes fases del proceso patológico o tal vez respondan a dosis, virulencia, coexistencia $y / o$ superinfecciones de neumopatógenos.

La destrucción epitelial de manera descendente comprometiendo traquea, bronquios, bronquiolos y alvéolos pueden ser consecuencia de replicación viral como el virus sincitial bovino y el PI-3 quienes utilizan células epiteliales en su desarrollo viral (Trigo, 1991; Bohlender et al., 1982; Bryson et al., 1983) La consecuente destrucción epitelial producto de replicaciones virales tal vez expliquen los diversos grados de traqueitis, bronquitis, bronquiolitis $\mathrm{y} / \mathrm{o}$ alveolitis observada en las lesiones neumónicas. También explicaría la moderada a severa descamación celular y la presencia de bronquiolitis obliterante (Cuadro 3 y Figura 8). Por otro lado, los depósitos fibrinosos $y / o$ fibrinopurulentas generalmente se atribuyen a infecciones bacterianas.

En las muestras patológicas estudiadas asociadas con pleuritis fibrinosa, engrosamiento del septo interlobulillar, 
con evidencias de inflamaciones agudas supurativas, necrotizantes y hemorrágicas se identificaron agentes virales y se aislaron consistentemente microorganismos del género Pasteurella. Estos hallazgos tienden a corroborar la asociación de cuadros neumónicos fibrinosos y supurativo con infecciones por Pasteurella hemolitica y $P$. multocida (Muñoz et al., 1987; Pedroso et. al., 1988; Cravens, 1993), pero la presencia de agentes virales sugiere que el establecimiento bacterial podría ser consecuencia de cambios iniciales ocasionados por agentes virales. La identificación de corpúsculos de inclusión y la presencia de células multinucleadas, citopatologías directamente asociadas a infecciones virales, e identificadas en algunas alteraciones patológicas en pulmones afectados indicaría que muchas de las alteraciones patológicas son directamente ocasionadas por replicaciones de agentes virales (Bohelender et al., 1982; Bryson et al., 1983).

La interacción múltiple de diversos agentes neumopatógenos en casos neumónicos de campo estudiados evidencian la presencia de coexistencia de varios agentes virales. En estas muestras se identificaron mayoritariamente pestivirus (BVD) y herpesvirus bovino (BHV) seguidos de ambos BRS y PI-3. Interesantemente, en el 95\% de los casos de observó asociaciones virales, casi en el $80 \%$ de estas asociaciones se detectaron simultáneamente hasta 3 virus neumopatógenos y en el $20 \%$ restante se lograron identificar hasta 2 agentes virales siendo la asociación del BVD y BHV-1 la más frecuente (Cuadro 4). La predominancia del virus del BVD en las muestras patológicas estudiadas fue mucho mayor de lo esperado, pero tiende a corroborar con los datos emergentes sobre la habilidad de este agente viral de producir cuadros neumónicos (Evermann et al., 1993).

Desde que el presente estudio ha buscado determinar el rol producto de la interacción virus y Pasteurella en síndromes neumónicos en bovino de engorde, la demostración de antígenos de los más importantes agentes virales tales como BVDV, BHV1, BRSV y PI-3 evidencia la presencia de estos virus en la etiología multifactorial de las neumonías en explotaciones de engorde limeños. La determinación de hasta $30 \%$ de animales con títulos de anticuerpos superiores a 1:32 (Cuadro 7) para muchos agentes virales demuestra que los animales se encontraban recientemente expuestos a los virus estudiados.

Por otro lado, la alta prevalencia de antígeno viral y de anticuerpos contra el virus de la diarrea viral bovina (BVDV es similar a lo observado en otros países (Houe, H. et al., 1995; Radostits y Littlejohns 1988; Roberts et al., 1991; Brownlie, 1991; Werdin et al., 1989). Esta prevalencia, sin embargo, es muy superior a lo observado en los Estados Unidos ( 26 y $39 \%$ de aislamientos en pulmones neumónicos) (Evermann et al., 1993). La diferencia se explicaría debido a que este último estudio se realizó mediante aislamiento viral y no detección de antígenos. En el Perú, el BVD la infección fue diagnosticado en la década del sesenta(Rivera, 1993; Sandoval, 1992) y fue responsable de brote respiratorio en terneros lecheros de Lima (Rivera et al., 1994). Los datos encontrados demuestran que el pestivirus bovino es uno de los principales agentes causales de brotes neumónicos en animales criados en sistemas intensivos propios de los centros engordes peruanos.

Los análisis antigénicos y serológicos no fueron diseñados para identificar determinadas variantes pero debe mencionarse que existen reportes sobre la existencia de la denominada cepa 2 del virus BVD con predilección por la mucosa respiratoria (Bolin y Ridpath, 1992; Brownlie, 1991). Se desconoce la fuente de infección viral para los animales que ingresan a los centros de engorde. Tal vez la infección provenga de los lugares de origen de estos animales o sean cepas introducidas a los centros de engorde mediante productos biológicos (vacunas) que se han venido utilizando ante la desesperación de 
controlar procesos neumónicos. Por otro lado, no existe datos de prevalencia del virus del BVD a nivel nacional pero se sabe que determinadas cuencas lecheras como Arequipa y Lima son altamente prevalentes a la infección que bien podrían ser introducidas por animales desde sitios de origen.

Debe mencionarse que los pestivirus en general son inmunosupresores. En algunos de los animales estudiados se logró observar disminuciones en recuentos leucocitario $(16 / 20)$ y depleción linfoide en ganglios linfáticos regionales (datos no mostrados) que podría ser resultado de la replicación viral. Estas alteraciones, sin embargo, no son exclusivamente pestiviral pues mecanismos similares pueden ser producidos por virus citolíticos como el BHV1 así como la leucotoxina de P.haemolytica y la liberación de esteroides producido durante los estados de estrés (García-Belenguer y Mormede, 1993).

La demostración elevada de antígenos herpéticos (BHV-1) $(75 \%, 15 / 20)$ de pulmones neumónicos y alta seroprevalencia no solamente verifica la amplia difusión de este virus en nuestro medio (Rosadio et al., 1993), también indica ser uno de los principales agentes responsables de las neumonías agudas en bovinos de engorde. Similares seroprevalencia se reporta en países con grandes centros de crianza intensiva y de engorde (Kramps et al., 1993). Sin embargo, la prevalencia reportada en el presente estudio es superior a lo observado en áreas lecheras como Cajamarca (19.20\%) (García, 1977), Lima (19\%) (Rivera et al., 1987) y sobre todo es superior a lo encontrado en bovinos carniceros del norte, centro y sur del país (36.5\%) (Rosadio et al., 1993). Estas aparentes diferencias quizás se expliquen a que nuestros análisis provienen de animales padeciendo signos clínicos de la enfermedad y de establecimientos sometidos a prácticas estresantes que sin lugar a dudas generaría reactivaciones virales en animales portadores de la infección herpética (Kramps et al., 1993).
Por otro lado, nuestros resultados confirman la alta prevalencia de virus con gran predilección por tejido pulmonar como el virus respiratorio sincitial bovino (BRSV) y el PI-3 ratifican que estos agentes circulan libremente en poblaciones de rumiantes peruanos. Estos resultados corroboran estudios realizados en poblaciones lecheras del Perú y de otros países (Van Nieuwstadt, 1983; Baker et al., 1986; Castleman et al., 1985; Welliver, 1988). Esta prevalencia, sin embargo es alta comparada a lo observada hace diez años en bovinos de engorde en el Perú (42\%) (Rivera et al., 1987). La alta seroprevalencia no solo demuestra experiencia de los animales frente a estos virus en sus lugares de origen también reflejaría constante actividad viral producto de periódica renovación poblacional propio de centros de engorde. Pero el compromiso viral en casos neumónicos es mucho más baja (25-35\%) que lo reportado anteriormente en terneros lecheros (19/25) (Kimman et al., 1989; Rivera et al., 1987). Esta diferencia sin lugar a dudas refleja a la alta predilección que tiene ambos virus del BRSV y PI-3 por poblaciones jóvenes y cierta resistencia que ofrecen los animales adultos componentes en nuestro estudio. La presencia de estos agentes virales es importante pues en forma aislada son capaces de producir infecciones ligeras pero fundamentalmente tiende a predisponer al tracto respiratorio a padecer superinfecciones con otros neumopatógenos como lo detectado en nuestro estudio.

Los métodos de aislamiento de pulmones afectados identificaron a la $P$. multocida como la bacteria frecuentemente recuperada. La predominancia de esta especie bacterial en tejidos afectados se refleja similarmente cuando se recupera bacteria utilizando hisopos nasales. Esta correlación entre aislamiento de tejido y recuperación bacterial de hisopados indica no solamente que la bacteria se encuentra proliferando en las vías respiratorias altas si no que además tiene una gran capacidad de descender al tracto respiratorio bajo para comprometer fatalmente las funciones respiratorias del 
hospedero. La mayor frecuencia de aislamiento por hisopados ofrece una buena alternativa para los estudios de Pasteurella en casos clínicos asociados con neumonías. Estas bacterias son comensales de la región nasofaringea, que en condiciones normales su multiplicación es inhibida por especies de la flora normal (Cravens, 1993; Welmersheimer, 1992; Martinez et al., 1988; Blanca et al., 1992; Nelson y Frank, 1989). Pero que en condiciones patológicas ocasionadas por infección viral o estrés de transporte, social, ambiental, etc. facilitarían la proliferación de cepas patógenas fácilmente excretadas en exudado nasal, y/o descenso para comprometer vías respiratorias profundas (Frank y Brigs, 1995; Frank et al., 1987; Frank et al., 1989; Ryu et al., 1984).

El porcentaje de aislamiento $(55 \%)$ de Pasteurella en el presente estudio, es similar a muchos reportes disponibles en la literatura. En todas las muestras estudiadas la bacteria siempre estuvo asociada con agentes virales. Estos resultados tienden a confirmar sobre el rol oportunista de esta bacteria en procesos neumónicos, pero su presencia generalmente se asocia con incremento en las tasas de fatalidades. No debe descartarse, sin embargo, que existen informaciones sobre evidencias de que algunas cepas de Pasteurella capaces de producir neumopatías sin la necesidad de agentes primarios virales. En nuestro estudio se ha aislado con mayores frecuencias cepas de $P$. multocida concordando con lo encontrado en países como México y Cuba. Pero se demuestra que la $P$. Haemolytica al parecer no es tan común como se reporta principalmente en países industrializados (Martinez et al., 1984; Fuentes y Pedros, 1986; Pedroso et al., 1987)

En las interacciones virus-Pasteurella, $(55 \%, 11 / 20)$ la combinación de dos virusPasteurella fue las más frecuente, Dentro de estas interacciones, la presencia simultánea de BVDV y P.multocida fueron las más frecuentes. Estos hallazgos confirman que los síndromes neumónicos en el campo, son productos de múltiples agentes que interactúan secuencialmente $y / o$ concomitantemente influenciados por el efecto patofisiológico de los diferentes tipos de estrés que experimenta el animal en los centros de engorde. Tal vez sean consecuencias de inmunosupresión fisiológica o viral y/o acción citolítica de los virus de tropismo respiratorio como Pl-3 ó BRSV ó BHV-1 u otro no determinado en nuestro estudio. La interacción virus bacteria se inicia con la entrada inicial del virus que causa daño de las células epiteliales, limitando o destruyendo los mecanismos de defensa intrapulmonares y/o facilitando la penetración de otro virus y/o Pasteurella. La colonización y/o proliferación bacterial quizás sea facilitada por la exposición de nuevos receptores celulares. Los mecanismos bactericidas llegan a deprimirse marcadamente casi una semana después de la infección viral. Sin embargo la proliferación de Pasteurella, quizá sea debida esencialmente a anormalidades en la ingestión y digestión intracelular por los macrófagos alveolares que son principal línea de defensa del pulmón y encargado de iniciar y regular la respuesta inmune local y sistémica.

Se menciona que $P$. haemolytica tiende a causar neumonía lobar fibrinosa y la $P$. multocida bronconeumonía fibrinopurulenta (Pedroso et al., 1988) pero estas afirmaciones suelen describir diferencias un tanto inconsistente pues ambas bacterias, pueden producir lesiones muy similares (Paulsen et al., 1989). Sin embargo, se argumenta que la necrosis coagulativa multifocal rodeada y demarcada por leucocitos es la lesión más patognomónica de $P$. haemolytica, mientras que producción mínima de necrosis y la gran infiltración neutrofílica es atribuida a $P$. multocida. En el presente estudio las lesiones macro y microscópicas no fueron distintivamente típicas, pero guardan relación con lo se describe como neumonía severa agudas (Muñoz et al., 1987; Pedroso et al., 1988; Cravens, 1993). Debe mencionarse, 
sin embargo, que se tratan de lesiones asociadas con múltiples agentes y no exclusivamente producidas por bacterias. Las lesiones severas observadas tales como pleuritis fibrinosa, severa y difusa engrosamiento del septo interlobulillar, con presencia de trombos fibrinosos y focos de necrosis coagulativa, así como hemorragia, congestión y edema estuvieron asociados con aislamiento de $P$. haemolytica, posiblemente relacionado a sus factores de virulencia como la endotoxina (Paulsen et al., 1989; Slocombe et al., 1989). Por otro lado, de las lesiones caracterizadas por deposición de fibrina e infiltración neutrofilica fueron similarmente recuperadas ambas especies bacterianas. Debe mencionarse sin embargo que se tratan de lesiones asociadas con aislamientos $y / o$ identificaciones de múltiples agentes y no de lesiones exclusivamente producidas por bacterias. Aunque tal vez, la infiltración neutrofilica produzca daños más extensos a consecuencia de liberaciones enzimáticas y/o productos metabólicos de las actividades fagocíticas encargadas de la arquitectura normal del tejido pulmonar.

Todos los casos de neumonías fatales observadas en los centros de engorde estuvieron asociados a procesos infecciosos. En el $95 \%$ de las muestras neumónicas estudiadas se comprobaron sinergismo virus/bacteria y fundamentalmente coexistencia de hasta 3 virus más Pasteurella. La presencia predominante del pestivirus bovino (BVD) corrobora el rol emergente del virus del BVD en procesos neumónicos y consolida al herpesvirus bovino (BHV-1), respiratorio sincitial bovino y el virus de la parainfluenza 3 (PI-3) como los principales agentes virales. La aparente fatalidad de estos casos se asoció con superinfecciones de la Pasteurella principalmente $P$. multocida. La etiología multifactorial en los procesos neumónicos no es nada nueva, pero evidencia la presencia de agentes con habilidades inmunosupresoras que conjuntamente con los factores estresantes propias del sistema intensivo de esta explotación explicarían las enormes pérdidas asociadas con procesos neumónicos en animales sometidos a sistemas de engorde. Las medidas de prevención en el manejo sanitario de estos animales tendientes a la disminución los efectos inmunosupresores sin lugar a dudas reducirán las fatalidades asociadas a procesos neumónicos.

\section{Agrebegmentos}

Los autores expresan su reconocimiento a los señores ganaderos de Lurin y Pachacamac que facilitaron los animales utilizados en el estudio. Además agradecemos a las Dras. Sonia Calle y Laura Urteaga por las facilidades del Laboratorio de Bacteriología, FMV-UNMSM. El estudio se ejecutó gracias a la financiación obtenida por el Consejo de Ciencias y Tecnología (CONCYTEC) y al International Foundation for Science (IFS) proyecto $\mathrm{B} / 1640-2$. 


\section{Zanabria, et al.}

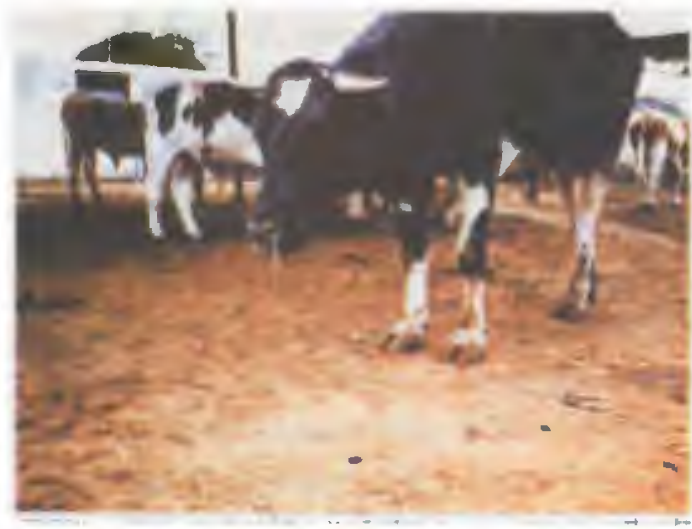

Figura 1. Animal padeciendo proceso neumónico. Obsérvese la severa depresión, cabeza y orejas caídas, secreción nasal bilateral mucopurulenta. El animal presentó cuadros de bronconeumonía y pleuritis y fue positivo a virus BHV1, BVDV más Pasteurella

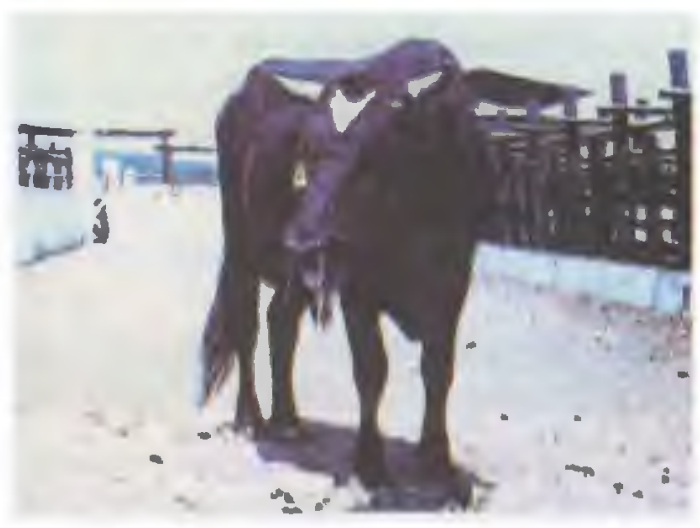

Figura 2. Animal afectado mostrando severa dísnea manteniendo cabeza extendida, respiración por y con la boca abierta, lengua protruida y salivación abundante. A la necropsia se observó cuadros de bronquitis y bronquiolitis obliterantes y positivo a tres virus: BHVI, BRSV y BVDV.

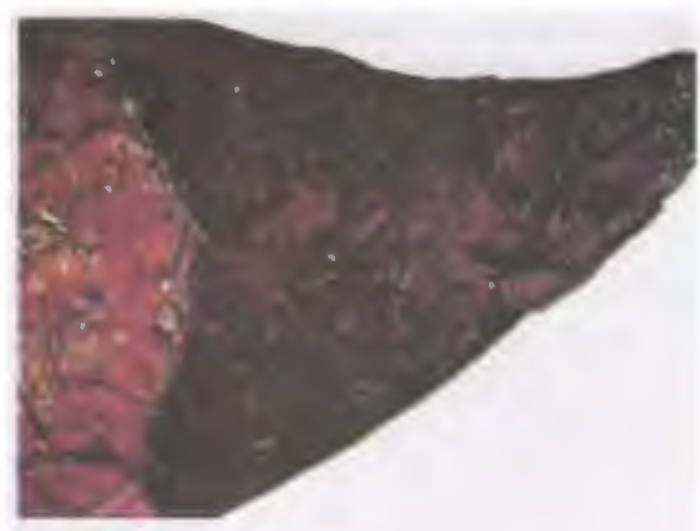

Figura 3. Severa numonía lobar comprometiendo extensivamente los lóbulos apicales, cardíacos y la parte ventral del lóbulo diafragmático.

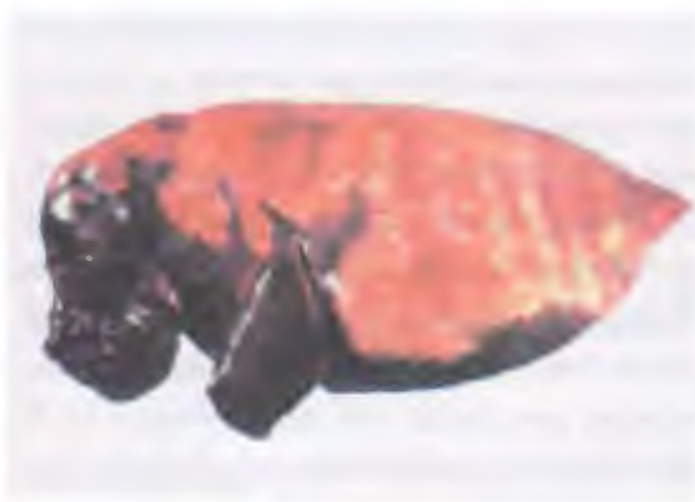

Figura 4. Detalles de neumonía lobar. Obsérvese consolidación, edema y pleuritis fibrinopurulento.

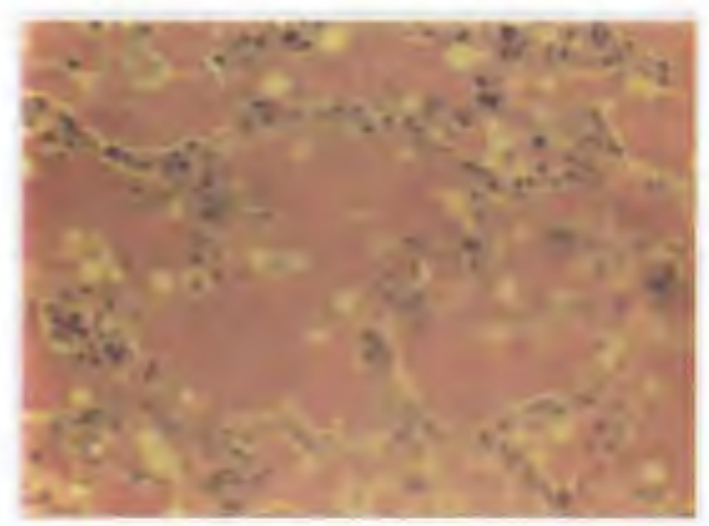

Figura 5. Tejido pulmonar. Nótese severo y extensivo edema asociado con infiltración predominante de polimorfonucleares. Muestra positiva a BHV1, BVD y $P$. haemolytica. Coloración H\&E. $10 \mathrm{X}$

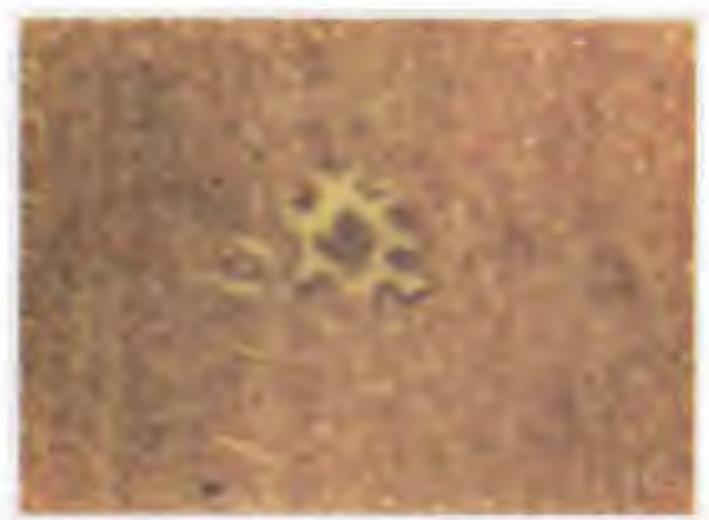

Figura 6. Tejido pulmonar afectado mostrando extensa consolidación pulmonar, degeneración y necrosis del epitelio bronquiolar y exudado imflamatorio intraluminal. Coloración H\&E $10 \mathrm{X}$ 


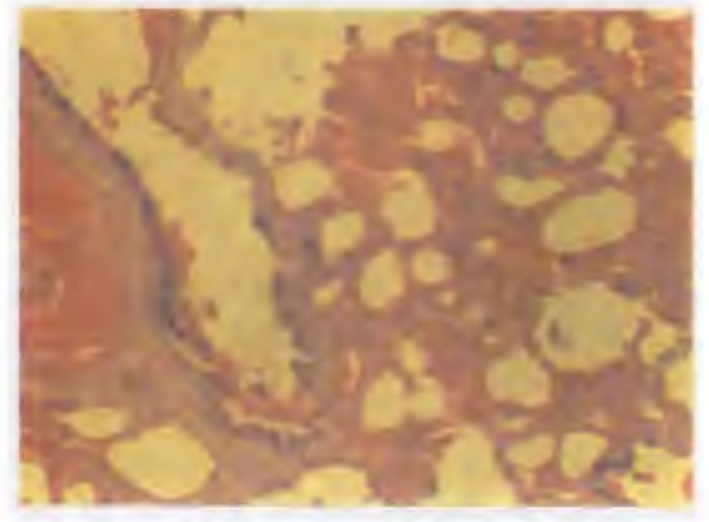

Figura 7. Tejido pulmonar afectado mostrando severa congestión y hemorragia difusa con escasa infiltración de células inflamatorias. Muestra positiva a BHV-1, BVD y $P$. haemolytica. Coloración H\&E 10X.

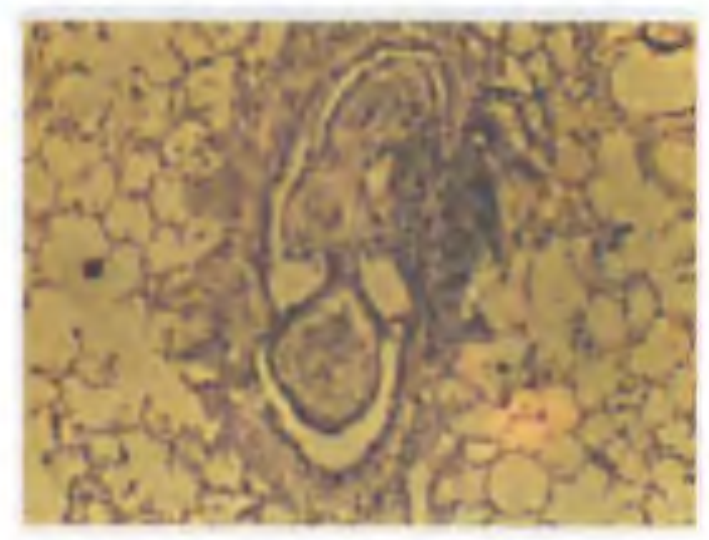

Figura 8. Tejido pulmonar afectado mostrando peribronquiolitis con formación de estructuras polipoides intrabronquiolar (bronquiolitis obliterante) Muestra positiva a HHV1, BVD y RSSV. Coloración H\&E. 10X.

\section{Literatura Citada}

1. Baker, J.C.; R.E. Werdin; T.R. Ames; R.J. Markla y V.L. Larson. 1986. Study on the etiologic role of bovine respiratory syncytial in pneumonia of dairy calves. JAVMA 189:66-70.

2. Biberstein, E.; P. Jangs; D. Kass y Hirsh. 1991. Distribution of indole - producing ureasa- negative Pasteurellas in animals J.Vet.Diagn. Invest.3:319-323.

3. Belknap, E.B.; D. Ciszewski y J.C. Baker. 1995. Experimental respiratory syncytial virus infection in calves and lambs. J. Vet. Diag. Invest.7:285-298.

4. Blanca, F.J.; F.J.Trigo; F. Suarez y G Tapia. 1992. Serotipos de Pasteurella

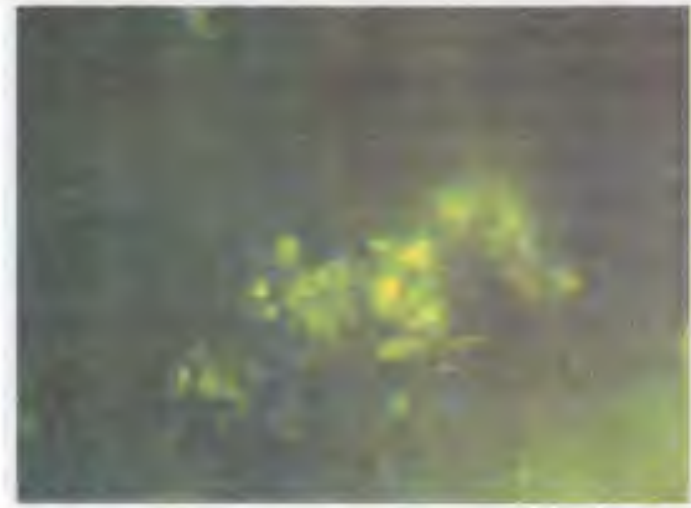

Figura 9. Microfotografía de tejido pulmonar positivo a la prueba de IF directa detectando corpúsculos intranucleares característica del herpesvirus bovino (BHV-1)

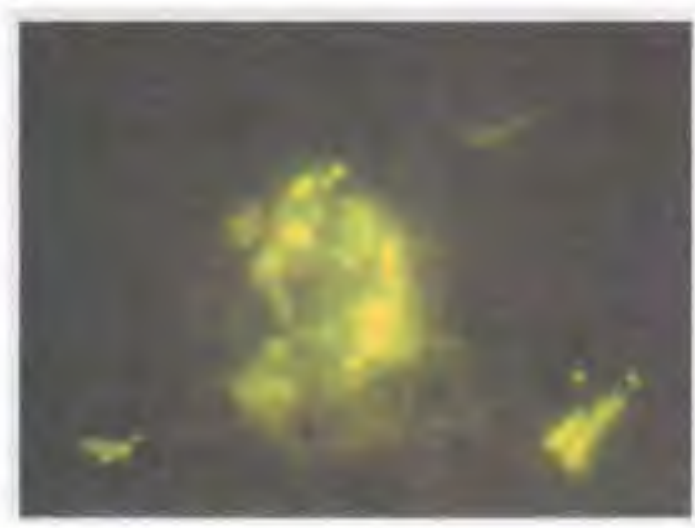

Figura 10. Microfotografia de tejido pulmonar positivo a la prueba de IF directa detectando corpúsculos intracitoplasmática característica del pestivirus bovino (BVD).

multocida y Pasteurella haemolytica aislados a partir de pulmones con lesiones neumónicas en rumiantes domésticos. Vet, Mex. 12(2):225.

5. Bohlender, R.E.; M. W. McCune y M.L. Frey. 1982. Bovine respiratory syncytial virus infection. Modern Vet. Pract. 63:613-618.

6. Bolin, S. y J. Ridpath. 1992. Differences in virulence between two noncytopathic bovine viral diarrhea viruses in calves. Am. J. Vet. Res. 53(11):2157-2163.

7. Brownlie, J. 1991. The pathways for bovine virus diarrhoea virus biotypes in the pathogenesis of disease. Arch. Virol 3:79-96. 
8. Bryson, D.G; M.S. McNulty; E.F. logany P.F. Cush 1983. Respiratory syncytial virus pneumonia in young calves: clinical and pathological findings. Am. J. Vet. Res. 44:1648-1655.

9. Castlesman, W.L.; Torres-Medina, A.; Hawkins, K.L.; Dubovi, E.J. y J.M. Atz. 1985. Severe respiratory disease in dairy cattle in New York State associated with bovine respiratory syncytial virus infection. Cornell Vet. 75:473-483.

10. Ciszewski, D.K.; J.C. Baker y R.F. Slocombe. 1991. Experimental reproduction of respiratory tract disease with bovine respiratory syncytial virus. Vet. Microb.:39-60.

11. Cravens, R. 1993. Pasteurella haemolytica vaccine takes aim at BRD:complex disease requires sophisticated product. Topics in Vet. Med. 4(2):16-24.

12. Cravens, R. 1993. Pasteurella haemolytica vaccine takes aim at BRD: clinical trials, field use affirm efficacy and safety. Topics in Veter. Med. 4(2):26-31.

13. Dyer, R.M. 1981. The bovine respiratory disease complex: infectious agents. Cont Education 3: S375-S381.

14. Evermann, J.; E. Berry; L.T. Baszlert; T. Byinton y P. Dilbeck 1993. Diagnostic aproaches for the detection of bovine viral diarhrea (BVD) virus an related pestiviruses. J. Vet. Diag. Invest. 5:265-269.

15. Fuentes, D.E. y M. Pedros. 1986. Vacuna contra la Pasteurelosis (Pasteurella multocida tipo A)II. Fracción capsular como inmunógeno. Rev.Salud Anim. la Habana. 8:2.

16. Frank, G. y Z.E. Brigs. 1995. colonization of the tonsils and nasopharynx of calves by a rifampicin resistant Pasteurella haemolytica and its inhibition by vaccination. Am J. Vet. Res. 56(7):866-879.

17. Frank, G.; S. Nelson y R. Briggs. 1989. Infection of the middle meatus of claves with Pasteurella haemolytica serotype I. Am. J. Vet. Res. 50:1297-1300.

18. Frank, G.; R. Briggs y K. Gillette. 1987. Pasteurella haemolytica serotype 1 colonization of the nasal passages of virus-infected calves. Am. J. Vet. Res. 48: 1674-1677.

19. Garcia, L.A. 1977. Encuesta serológica sobre rinotraqueitis infecciosa de los bovinos de la cuenca lechera de Cajamarca [Tesis Bach] Fac. Med. Vet; Univ. Nac.
Mayor San Marcos Lima:38

20. García-Belenguer, S. y P. Mormede. 1993. Nuevo concepto de estrés en ganadería: Psicobiología y Neurobiología de la adaptación Invest. Agr. Prod, Sanid. Anim 8(2):87-109.

21. Genicot, B.; F. Mouligneau; F. Rollin, R. Close y P. Lekeux. 1993. Economic, clinic and functional consecuences of a treatment using metrenperone during an outbreak of shipping Fever in cattle. The Vet. Rec (6): 245-247.

22. Houe, H.; J. Baker; R. Maes; H. Wuryastuti; R. Wasito; P. Ruegg y J. LLoyd. 1995. Prevalence of cattle persistently infected with bovine viral diarrhea virus in 20 dairy herds in two countries in central Michigan and comparation of prevalence of antibody positive cattle among herds with different infection and vaccination status. J Vet. Diagn. Invest. 7:321-326.

23. Kimman, T.G.; P.J. Straver y G.M. Zimmer, 1989. Pathogenesis of naturally acquired bovine respiratory sincytial virus infection in calves: Morphologic and serological finding. Am J. Vet. Res. 50(5):684-693.

24. Kimman, T.G; G.K. Terpstra; M.R. Daha y F. Westenbrink. 1989. Pathogenesis of natural acquired bovine respiratory syncytial virus infection in valves: Evidency for the involvement of complement and most of cell mediators. Am J. Vet. Res: 50:694-699.

25. Kramps, J.A.; Q. Weerdmeester y J. Van Oirschot. 1993. Comparative study on sixteen enzime-linked inmunosorbent assays for the detection of antibodies to bovine herpesvirus 1 in cattle. Vet. Microb. 35:11-21.

26. Martinez, A.; E. Aznar y C. Viña. 1988. Pasteurella multocida en tracto respiratorio de terneros Rev. Salud Anim. La Habana. 10:93-97.

27. Muñoz, M.C.; R. Joa y M. Pedroso. 1987. Evaluación en condiciones controladas de una vacuna contra Pasteurella multocida tipo A en ternerosmorfopatología. Rev.Salud Anim la Habana. 9:343-350.

28. Mulkey, K.M. y GA. Anderson. 1991. Monoclonal antibodies to the fusion protein of bovine respiratory syncytial virus 
J. Clin. Microbiol. 29:2038-2040

29. Nelson, S. y G. Frank. 1989. Bovine serum and nasal secretion immunoglobulins against Pasteurella haemolytica serotype 1 antigens. Am. J. Vet. Res.50:1244-1248.

30. Paulsen, D.; D. Mosier $y$ K. Clinkenbeard. 1989. Direct effects of Pasteurella haemolytica lipopolysaccharide on bovine pulmonary endotelial cells in vitro. Am. J. Vet. Res. 50:1633-1636.

31. Pedroso, M.; O. Fuentes; M. Quintana y E. Aznar. 1987. Reproducción Experimental de Neumonía (Pasteurella multocida tipo A) en terneros Rev.salud Anim. La Habana 9:13-19.

32. Pedroso, M.; O. Fuentes; M.C. Muñoz y M.A. Abeledo. 1988. Vacuna contra Pasteurella multocida tipo A para terneros: Evaluación de tres vías de administración local. Rev. Salud Anim. La Habana 10:93-97.

33. Pierson, R.E. y R. Kainer. 1980. Clinical classification of Pneumonias in cattle. Bovine Practitioner. 15:73-79.

34. Radostits, O. y I. Littlejolins. 1988. New concepts in the pathogenesis, diagnosis and control of disease caused by the bovine viral diarrhea virus. Can Vet J 29:513-528.

35. Richer, L y P. Marois. 1988. Association of bovine viral diarrhea virus with multiple viral infections in bovine respiratory disease outbreaks. Can Vet J 29:713-717.

36. Rivera, H.; A. Manchego; N. Sandoval; C. Morales y E. Flores. 1994. Complejo respiratorio bovino en terneros del valle de Lima. Rev. Inv. Pec IVITA. 7:35-38.

37. Rivera, H. 1993. El virus de la Diarrea viral bovina (BVD). Rev. Inv. Pec IVITA $6(1): 1-7$

38. Rivera, H.; H. Andresen y J. Levano. 1987. Prevalencia de anticuerpos a Rinotraqueitis infecciosa bovina (IBR), Parainfluenza 3(PI-3) y virus respiratorio sincitial (RSV), en bovinos de Lima. Res. Cong. Cien Vet. Perú: 18.

39. Rimler, R. y K. Rhoades. 1989. Pasteurella multocida. Pasteurella and Pasteurellosis. Academic Press limited, USA 35-73.

40. Roberts, K.; J. Collins; J. Carman y C. Blair. 1991. Detection of cattle in- fected with bovine viral diarrhea virus using nucleic acid hybridization $J$ Vet Diagn Invest 3:10-15.

41. Rosadio, R.; H. Rivera y A. Manchego. 1993. Prevalence of neutralizing antibodies to bovine herpesvirus- 1 in Peruvian livestock. The Vet Record. 12:611-612.

42. Ryu, H.; M.L. Kaeberl y A. Roth. 1984. Effect of type A Pasteurella multocida Fractions on Bovine Polymorphonuclear leucocyte Functions. Infection and immunity 43:70-71.

43. Sandoval, N. 1992. Seroprevalencia del virus BHV-1 (IBR) en vacas con historia de abortos y sin historia de abortos de la cuenca lechera de Lima [Tes.Bach.] Fac.Med.Vet. Univ. Nac. Mayor San Marcos: 39

44. Slocombe, RF; F.J. Derksen y N.E. Robinson. 1989. Comparison of Pathophysiologic changes in the lungs of calves challenge exposed with Escherichia coliderived endotoxin and Pasteurella haemolytica, alone or in combination. Am. J. Vet. Res. 50(5):701-707.

45. Trigo, F.J. 1991. Patogénesis y aspectos inmunológicos de la Pasteurelósis Pulmonar bovina. Vet. Méx. 22(2):131-133.

46. Van Nieuwstadt, A. D. 1983. Serology for diagnosis and epizootiological studies of bovine respiratory syncytial virus infections. Res in Vet Sci 35:153-159.

47. Welliver, R.C. 1988 . Detection, pathogenesis, and therapy of respiratory syncytial virus infection. Clinical Microbio Review 1:27-39.

48. Welmersheimer, JE. 1992. Liofilización con dos diferentes soportes como método de conservación de semilla de Pasteurella multocida. Téc. Pec. Méx. 3:255-257.

49. Werdin, R. G.S. Amest, G Devries. 1989. Diagnostic investigation of bovine viral diarrhea infection in a Minnesota dairy herd. J. Vet. Diagn. Invest. 1:57-61.

50. Yates, W.D., L.A. Babiuk, K.W. Jericho. 1983. Viral-bacterial pneumonia in calves: duration of the interaction between bovine herpesvirus 1 and Pasteurella haemolytica. Can. J. Comp. Med. 47:257-264. 